6-13-2001

\title{
A Numerical Model for the Cyclic Instability of Thermally Grown Oxides in Thermal Barrier Systems
}

Anette M. Karlsson

Cleveland State University, a.karlsson@csuohio.edu

A. G. Evans

Fillowethis and addditional works at: https://engagedscholarship.csuohio.edu/enme_facpub

Part of the Mechanical Engineering Commons

How does access to this work benefit you? Let us know!

\section{Publisher's Statement}

NOTICE: this is the author's version of a work that was accepted for publication in . Changes resulting from the publishing process, such as peer review, editing, corrections, structural formatting, and other quality control mechanisms may not be reflected in this document. Changes may have been made to this work since it was submitted for publication. A definitive version was subsequently published in PUBLICATION, [VOL\#, ISSUE\#, (DATE)]; NOTICE: this is the author's version of a work that was accepted for publication in Acta Materialia. Changes resulting from the publishing process, such as peer review, editing, corrections, structural formatting, and other quality control mechanisms may not be reflected in this document. Changes may have been made to this work since it was submitted for publication. A definitive version was subsequently published in Acta Materialia, 49, 10, June 13, 2001; 10.1016/ S1359-6454(01)00073-8

\section{Original Citation}

Karlsson, A. M., and Evans, A. G., 2001, "A Numerical Model for the Cyclic Instability of Thermally Grown Oxides in Thermal Barrier Systems," Acta Materialia, 49(10) pp. 1793-1804.

This Article is brought to you for free and open access by the Mechanical Engineering Department at EngagedScholarship@CSU. It has been accepted for inclusion in Mechanical Engineering Faculty Publications by an authorized administrator of EngagedScholarship@CSU. For more information, please contact library.es@csuohio.edu. 


\title{
A NUMERICAL MODEL FOR THE CYCLIC INSTABILITY OF THERMALLY GROWN OXIDES IN THERMAL BARRIER SYSTEMS
}

\author{
A. M. KARLSSON $\dagger$ and A. G. EVANS \\ Princeton Materials Institute, Princeton University, Princeton NJ 08540, USA
}

\section{INTRODUCTION}

Thermal barriers are widely used in turbines for propulsion. They comprise a thermally insulating coating having sufficient thickness and durability to sustain an appreciable temperature difference between the load bearing alloy and the surface. Their benefit resides in an ability to sustain thermal gradients in the presence of adequate back-side cooling. Lowering the temperature of the metal substrate prolongs the life of the component. Reviews of thermal barrier systems, including their durability and failure modes may be found in [1-6]. There are four primary constituents in a thermal barrier system:

1. the thermal barrier coating (TBC) itself;

2. the superalloy substrate;

3. an aluminum containing bond coat between the substrate and the TBC; and

4. a thermally grown oxide (TGO) that forms between the TBC and the bond coat.

The TBC is the insulator, the bond coat provides the oxidation protection and the alloy sustains the structural loads. The TGO is a reaction product. Each of these elements is dynamic and all interact to control

\footnotetext{
$\uparrow$ To whom all correspondence should be addressed. E-mail address: karlsson@princeton.edu (A.M. Karlsson)
}

the durability. The TGO develops extremely large residual compressions (3-6 GPa) $[4,7]$ as the system cools to ambient, primarily because of its thermal expansion misfit with the substrate. Stresses may also arise during growth.

The bond coat emphasized in this study comprises a Pt-modified diffusion aluminide, fabricated by electroplating a thin layer of $\mathrm{Pt}$ onto the superalloy substrate and then aluminizing by chemical vapor deposition [4]. These coatings are single-phase $\beta-\mathrm{NiAl}$, with $\mathrm{Pt}$ in solid solution. The composition evolves during service. In particular, diffusion of $\mathrm{Al}$ to form $\alpha$-alumina results in the formation of $\gamma-\left(\mathrm{Ni}_{3} \mathrm{Al}\right)$ domains [8]. Morphological instability of the TGO is a dominant failure mode in systems comprising $\beta$ NiAl [6, 8-13]. That is, some initial non-planarities in the TGO grow in amplitude, $A$, as the system experiences thermal cycling. As this happens, strains are induced in the TBC that cause cracks to form and extend laterally. Eventually, cracks from neighboring sites coalesce, causing large scale buckling and failure of the TBC [6]. Two fundamental factors underlie the phenomenon [9]. (a) The displacements must be accommodated by plastic deformation of the bond coat, through flows from the base of the undulations to the sides. (b) Within the undulations, the TGO must exhibit growth strains both parallel and normal to the interface with the bond coat, in order to account for its increased length and thickening, respectively. The thermal expansion misfit between the TGO and 
the substrate motivates the instability because, at ambient temperatures, the TGO becomes residually compressed and is unstable against increases in length [6]. The challenge is to understand how these effects interrelate and to derive mechanism-based solutions for the cyclic changes in amplitude.

Two basic ideas for the morphological instability have been put forward. One of these visualizes the phenomenon as ratcheting [9-13]. This is manifest as cyclic plastic displacement upon cooling and heating, vectored into the bond coat by the lateral growth strain in the TGO. The other imagines a volume decrease caused by a localized phase change (from $\beta$ to $\gamma^{\prime}+\beta$ ), upon TGO formation, that results in its downward displacement [8]. The present article elaborates on the first concept by developing a simulation scheme capable of probing a range of mechanistic possibilities.

Two prior investigations $[9,10]$ have illustrated that morphological instabilities can be linked to thermal cycling and TGO growth, but both were limited in applicability by material and geometrical simplifications. An original analysis identified general requirements and responses [9], but subject to the following limitations: The surface had sinusoidal undulations, amplitude $A$ and wavelength, $L$; The bond coat had temperature independent yield strength, $\sigma_{\mathrm{Y}}^{\mathrm{bc}}$, Young's modulus, $E_{\mathrm{bc}}$, and thermal expansion coefficient, $\alpha_{\mathrm{bc}}$. The substrate had the same properties as the bond coat; the TGO was considered elastic with Young's modulus, $E_{\text {tgo }}$, and thermal expansion coefficient, $\alpha_{\text {tgo }}$. To simulate oxidation, the TGO was allowed to undergo an isotropic growth strain at the highest temperature in the thermal cycle. A subsequent analysis [10], relaxed some of the material restrictions, but required a major geometric simplification. Namely, by reverting to spherical symmetry, the TGO was modeled as an annular domain embedded within the bond coat. This allowed derivation of analytical results for stresses and plastic zone sizes that provided key additional insights. Another innovation was the introduction of a growth strain that depended on the in-plane stress in the TGO induced at the maximum temperature in the cycle. The present analysis sets out to eliminate the restrictions of the previous models within a tractable numerical scheme. It uses imperfections having realistic geometric characteristics, with material properties representative of actual thermal barrier systems.

\section{THE SIMULATION SCHEME}

\subsection{The approach}

The model is depicted in Fig. 1. It consists of an axi-symmetric undulation in the bond coat with external (periodic) boundaries enough large to assure a negligible interaction between imperfections. The substrate is deep enough to suppress overall bending. To simulate an oxidation process wherein most of the new TGO forms at the interface, but a small amount may form internally, within the prior TGO [7, 13, 14], an anisotropic growth law is used. The magnitude of the strain per cycle normal to the interface, $\epsilon_{\mathrm{t}}$ (which governs the thickening), is taken to be much larger than the strain per cycle, $\epsilon_{\mathrm{g}}$, parallel to the interface (which causes lengthening of the TGO and induces the growth stress). Moreover, in order to limit the growth stress to levels found experimentally [4, 7], the TGO is allowed to undergo high temperature stress relaxation. This is realized by assigning a yield strength, $\sigma_{Y}^{\text {tgo }}$, at the peak temperature, and allowing it to rise rapidly with decrease in temperature, such that at lower temperature, the TGO behaves as an elastic medium. The details are elaborated later. This protocol assures that the high temperature (growth) stress in the TGO never exceeds $\sigma_{Y}^{\text {tgo }}$, but allows larger stresses to develop on cooling. It will be shown below the growth stress attains $\sigma_{Y}^{\text {tgo }}$ (in compression) on flat sections and that the stresses induced at ambient are consistent with measured values $[4,6]$. In order to attain as much simplicity as possible, and yet retain the essence of the combined effects of growth and cycling, the thickening per cycle, $\epsilon_{\mathrm{t}}$, is taken to be small enough that the total TGO thickening is less than the initial thickness. The effects of large increases in thickness are being addressed in a subsequent study.

For some of the preliminary calculations, the bond coat is assumed to have a temperature invariant yield strength. The results for this case are used to affirm some of the previous calculations $[9,10]$ as well as to demonstrate the characteristics of the instability for a more representative geometry, subject to a more complete representation of the TGO. With these effects established, the influence of a temperature dependent yield strength is explored, in accordance with trends found for prototypical bond coats (Fig. 2) $[15,17]$. Furthermore, the effect of the mismatch in thermal expansion between substrate and bond coat [16] is analyzed and discussed.

Cracking of the TGO is not included in the present version of the model. This does not appear to be a major limitation, since cracks are only observed in regions exhibiting severe ratcheting [13]. An embellishment based on thin film cracking criteria will be introduced in a later version.

\subsection{The numerical method}

The simulations have been conducted by using the finite element method, employing the commercially available code ABAQUS. Four-node axi-symmetric, bi-linear elements are used. The axis of symmetry is at the center of the undulation, with periodic boundary conditions (Fig. 1). The undulation has been assigned a representative shape and size (Fig. 1) $[4,6,8,13]$ : radius, $R_{\mathrm{o}}=6 \mu \mathrm{m}$ and initial amplitude, $A_{\mathrm{o}}=2.4 \mu \mathrm{m}$. The surface of the TGO facing the TBC is left traction free. Because of its low stiffness [6], the TBC is assumed to have a minor effect on the 


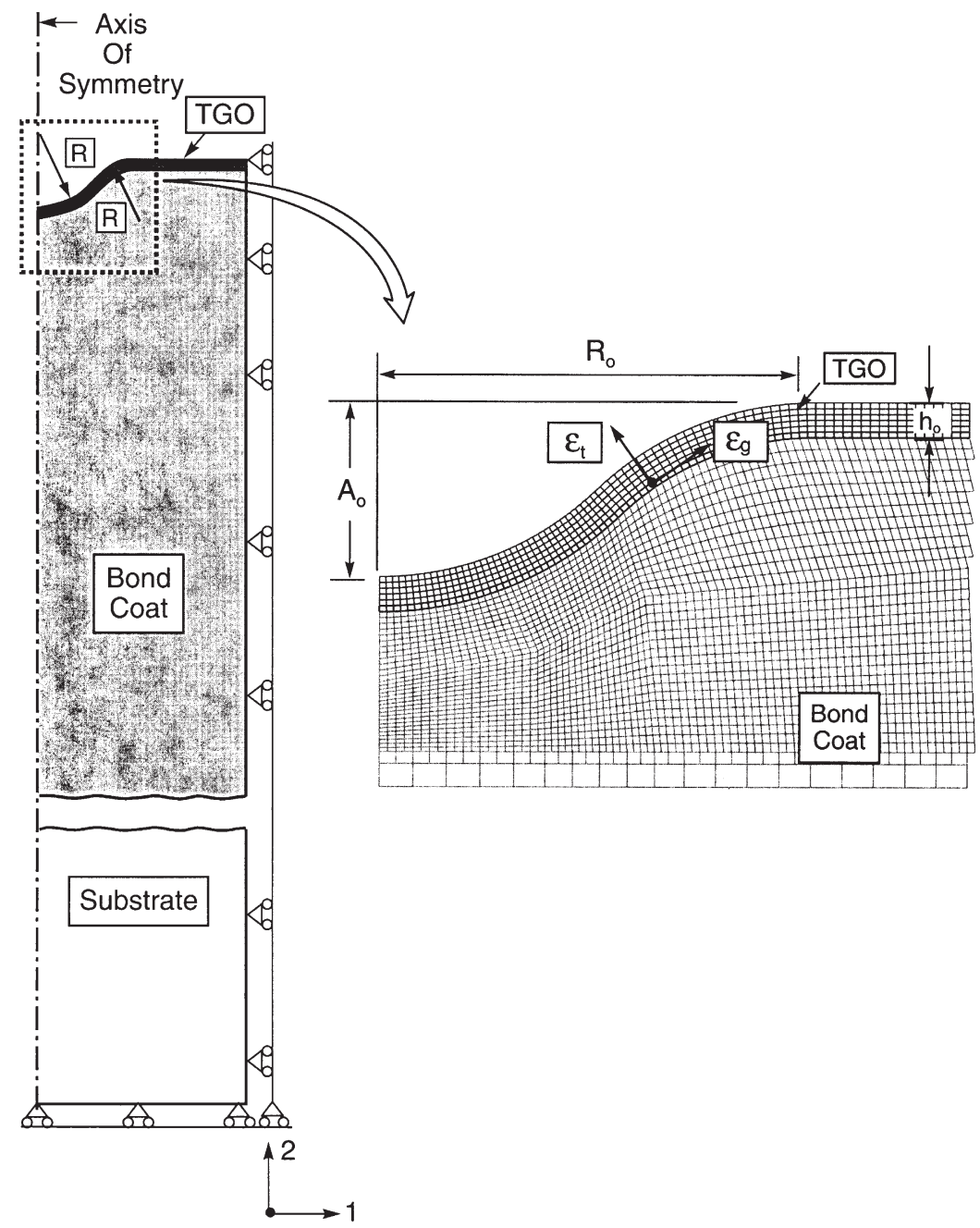

Fig. 1. The geometry used in the analysis, with the boundary conditions indicated.

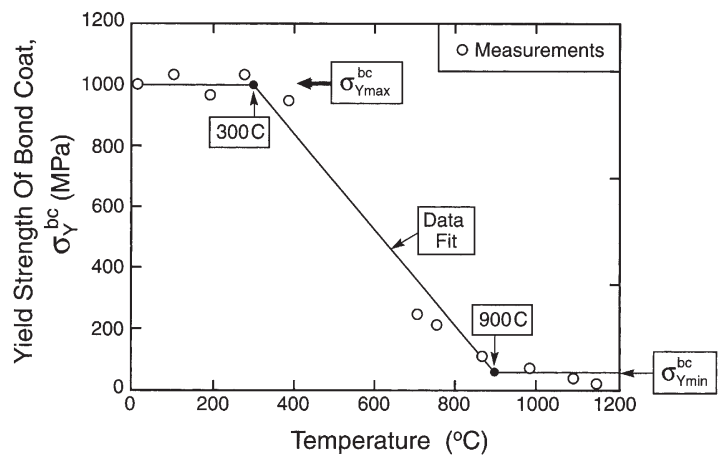

Fig. 2. Typical temperature dependent yielding in the bond coat, showing the fit used for the simulations [15].

general behavior: the specific effects of the TBC will be addressed in a later study.

Growth of the TGO is simulated by imposing stress-free strains in accordance with a user subroutine, uexpan. It consists of two components, $\epsilon_{\mathrm{g}}$ and $\epsilon_{\mathrm{t}}$. The in-plane component, $\epsilon_{\mathrm{g}}$, is assumed to be spati- ally uniform through the TGO-thickness. This strain duplicates the formation of new oxide along the grain boundaries of a columnar-grained TGO [4, 6, 8]. Thickening of the TGO is modeled by adding a strain, $\epsilon_{\mathrm{t}}$, in the row of TGO elements next to the bond coat $\dagger$. The TGO thickness after $N$ cycles is thus:

$$
h=h_{0}+h_{0}^{e}\left[(N-1) \epsilon_{\mathrm{t}}\right]
$$

where $h_{0}$ is the initial thickness of the TGO, and $h_{0}^{e}$ is the element thickness (equal to $1 / 6 h_{0}$, since the oxide is modeled by six elements in its thickness). Note that no growth strain is applied in the last cycle

$\dagger$ Hence, the total strain, $\epsilon_{\text {tot }}$, can be divided into four components, $\boldsymbol{\epsilon}_{\mathrm{tot}}=\boldsymbol{\epsilon}_{\mathrm{E}}+\boldsymbol{\epsilon}_{\mathrm{P}}+\boldsymbol{\epsilon}_{\mathrm{G}}+\boldsymbol{\epsilon}_{\mathrm{T}}$, where $\boldsymbol{\epsilon}_{\mathrm{E}}$ is the elastic strain, $\boldsymbol{\epsilon}_{\mathrm{P}}$ the inelastic strain, $\boldsymbol{\epsilon}_{\mathrm{G}}$ is the strain caused by the oxide growth, and $\boldsymbol{\epsilon}_{\mathrm{T}}$ is the thermal strain. In addition, the strain caused by the oxide growth may be divided into two components, $\epsilon_{\mathrm{G}}=\epsilon_{\mathrm{\perp}} \boldsymbol{e}_{\perp}+\epsilon_{\mathrm{g}} \boldsymbol{e}_{\|}$, where $\boldsymbol{e}_{\perp}$ is perpendicular and $\boldsymbol{e}_{\|}$is parallel to the TGO/BC interface. Note that $\boldsymbol{\epsilon}_{\mathrm{G}}$ and $\boldsymbol{\epsilon}_{\mathrm{T}}$ are both stress free strains. 
Table 1 . Summary of material properties

\begin{tabular}{lccc}
\hline & Young's modulus $(\mathrm{GPa})$ & Poisson ratio & $\begin{array}{c}\text { Thermal expansion coefficient } \\
\left(\mathrm{ppm} /{ }^{\circ} \mathrm{C}\right)\end{array}$ \\
\hline TGO & 380 & 0.2 & 8.4 \\
Bond coat & 190 & 0.3 & $11,14.3,17$ \\
Substrate & 190 & 0.3 & 14.3 \\
\hline
\end{tabular}

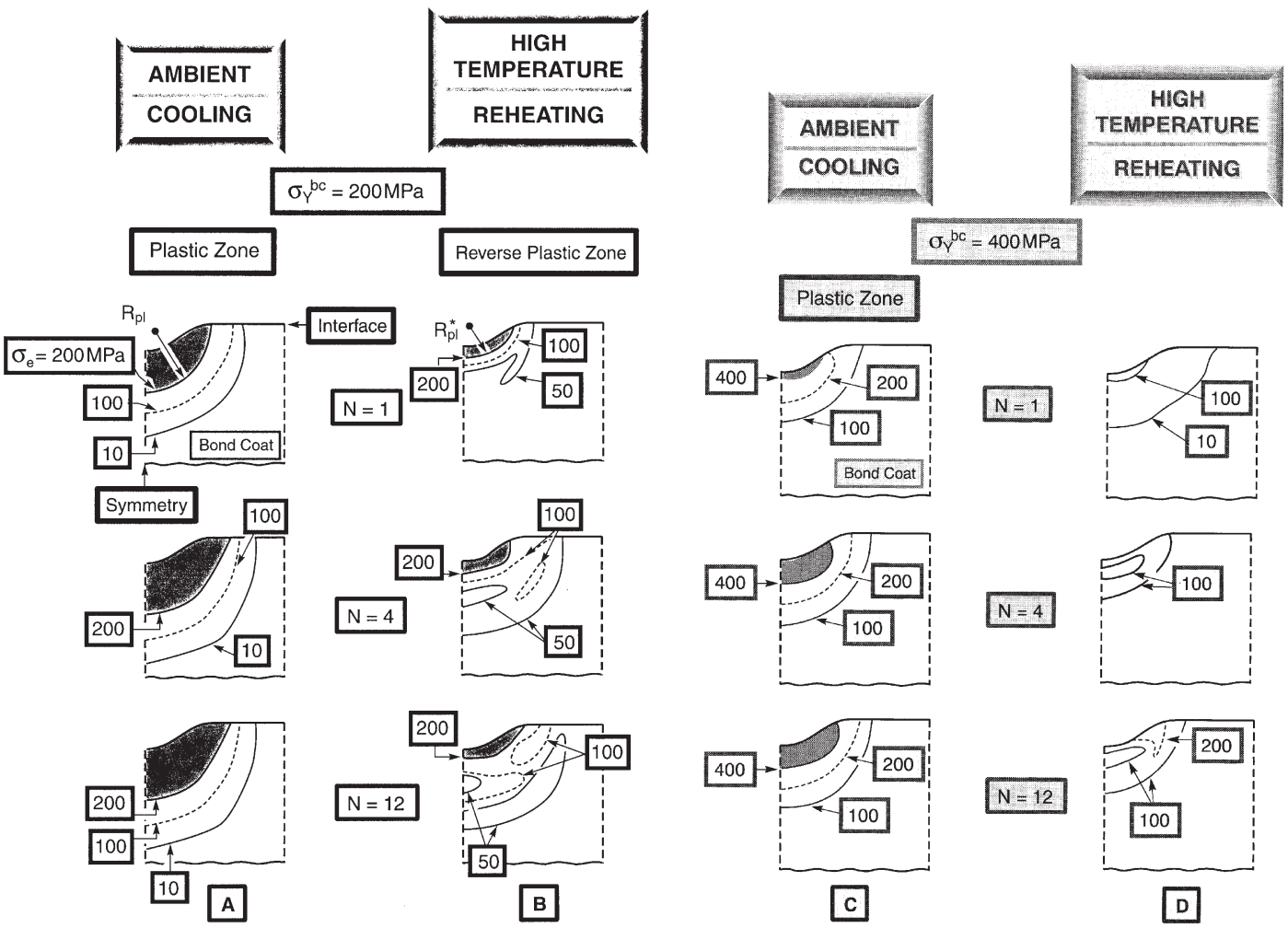

Fig. 3. A synopsis of the evolution of the yield zone and effective stresses in the bond coat over 12 cycles. For $\sigma_{\mathrm{Y}}^{\mathrm{bc}}=200 \mathrm{MPa}$ : (A) stress state at ambient, with the forward yield zone $R_{\mathrm{pl}}$ and (B) stress state at peak temperature with the reverse yield zone $R_{\mathrm{pl}}^{*}$. For $\sigma_{\mathrm{Y}}^{\text {bc }}=400 \mathrm{MPa}$ : (C) stress state at ambient with the forward yield zone $R_{\mathrm{pl}}$ and (D) stress state at peak temperature (note the lack of a reverse yield zone for this case).

(therefore $\epsilon_{\mathrm{t}}$ is qualified by $N-1$ ). The fraction, $\beta$, of the new oxide that forms internally

$$
\beta=\frac{\epsilon_{\mathrm{g}}}{\epsilon_{\mathrm{t}}}
$$

is assumed to be independent of the TGO thickness. In this study $\beta=10$. The growth strain is allowed to vary within the range found experimentally, $10^{-4}<\varepsilon_{\mathrm{g}}<5 \times 10^{-3}[13]$. The growth stress in the TGO is restricted to $\sigma_{\mathrm{Y}}^{\text {too }}= \pm 1 \mathrm{GPa}[6,7] \dagger$.

The bond coat is taken to be $50 \mu \mathrm{m}$ thick $[4,6,8$, 13] and assumed to be elastic/perfectly plastic. For cases that explore the temperature dependence of yielding (Fig. 2), the yield strength is incorporated by

$\dagger$ This is done by letting $\sigma_{Y}^{\text {tgo }}=10 \mathrm{GPa}$ for $T<900^{\circ} \mathrm{C}$, $\sigma_{\mathrm{Y}}^{\text {to }}=1 \mathrm{GPa}$ for $T \geqslant 1000^{\circ} \mathrm{C}$, and letting $\sigma_{\mathrm{Y}}^{\text {tgo }}$ vary linearly in between. specifying the maximum allowable Mises stress at each temperature. The substrate is taken to be elastic.

The thermo-elastic properties used in the calculations are summarized on Table 1. The calculations begin with a thin TGO, typical of that found after TBC deposition (thickness, $h_{0}=0.5 \mu \mathrm{m}$ ) $[4,6,13]$. Initially, the structure is stress-free at $1000^{\circ} \mathrm{C}$. It is cooled to $0^{\circ} \mathrm{C}$, reheated to $1000^{\circ} \mathrm{C}$ and TGO growth imposed. This sequence (three steps in ABAQUS) is repeated 12 or 24 times.

\section{SIMULATIONS}

\subsection{Temperature independent yielding}

3.1.1. Cyclic plastic response of the bond coat. The first results are for a case wherein the bond coat and substrate have the same thermal expansion coefficient. The effects of an expansion misfit are considered in Section 3.2. For simplicity of presen- 
tation, unless otherwise indicated, all of the following results are for a growth strain, $\epsilon_{\mathrm{g}}=10^{-3}$. The evolution of the plastic zone in the bond coat, as well as the associated plastic strains, and the imperfection amplitude are monitored in the calculations. A synopsis of results obtained for a yield strength, $\sigma_{\mathrm{Y}}^{\mathrm{bc}}=200 \mathrm{MPa}$, over 12 thermal cycles, is presented in Figs 3-8. This combination of results reveals that, at this yield strength, the imperfection depth, the plastic strains and the plastic zone all continue to enlarge as the system thermally cycles.

The plastic zone that forms on cooling has approximate spherical symmetry, with effective radius, $R_{\mathrm{pl}}$, as depicted in Fig. 3A. For this choice of parameters, reverse yielding occurs on re-heating (Fig. 3B), with effective radius, $R_{\mathrm{pl}}^{*}$. The evolution of the plastic zone upon cooling and reheating over 12 cycles is plotted on Fig. 4A. During the first cycle, yielding commences on cooling at a temperature, $T_{\text {cool }} \approx 580^{\circ} \mathrm{C}$, while reverse yielding on heating begins at a tempera-

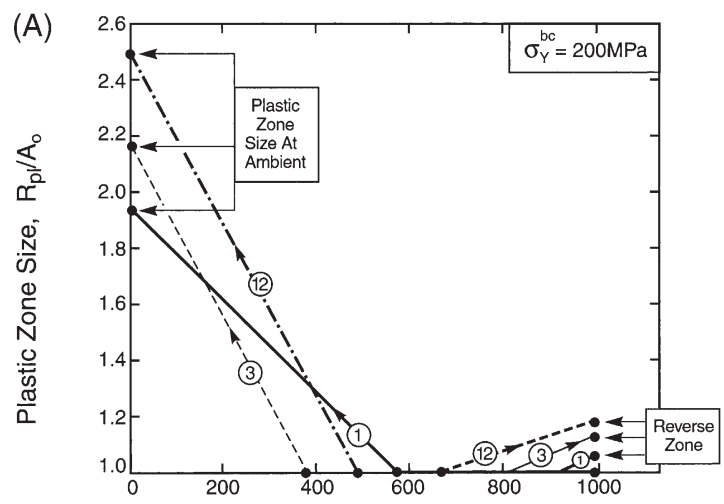

Temperature $\left({ }^{\circ} \mathrm{C}\right)$

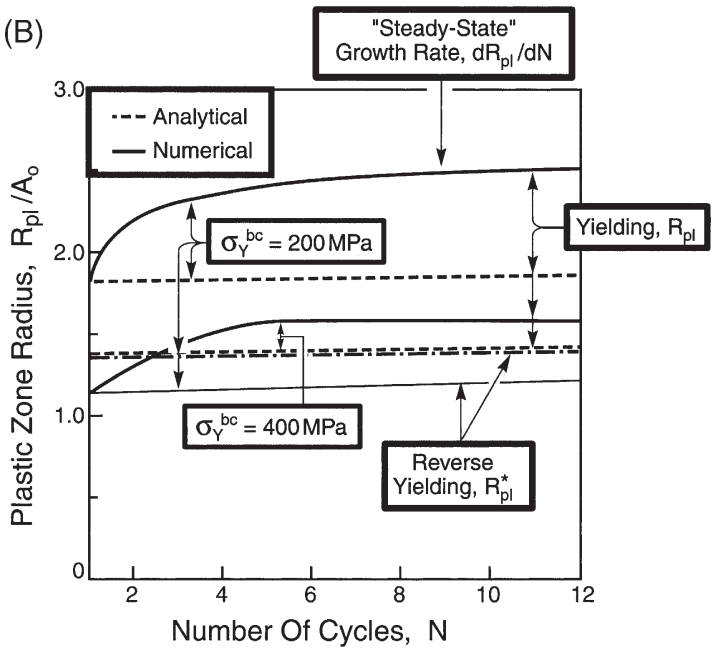

Fig. 4. (A) The development of the plastic zone, $R_{\mathrm{pl}} / A_{0}$, during thermal cycling (first, third and twelfth cycle). (B) The change with thermal cycling of the forward plastic zone, $R_{\mathrm{pl}} / A_{0}$, at ambient temperature and the reverse plastic zone, $R_{\mathrm{pl}}^{*} / A_{0}$, at the temperature maximum $\left(\sigma_{\mathrm{Y}}^{\mathrm{bc}}=200 \mathrm{MPa}\right)$. Analytical results from Ref. [10] are also shown. ture, $T_{\text {heat }} \approx 920^{\circ} \mathrm{C}$. As cycling proceeds, the system adjusts in the following manner. On cooling, the zone enlargement rate, $\mathrm{d} R_{\mathrm{pl}} / \mathrm{d}(-T)$, increases to a "steadystate". As this occurs, for the first few cycles, $T_{\text {cool }}$ decreases, but thereafter increases. Consequently, the zone size at ambient increases systematically with $N$ (Fig. 4B) and, after a few cycles, the rate, $\mathrm{d} R_{\mathrm{pl}} / \mathrm{d} N$, reaches a "steady-state". Coincident with these changes, upon re-heating, $T_{\text {heat }}$ decreases, causing $R_{\mathrm{pl}}^{*}$ to increase with increase in $N$, as indicated on Fig. 4B. Comparisons of the analytical estimates for the plastic zone sizes [10] with the numerical results (Fig. 6) reveal reasonable consistency. That is, the analytical prediction of the zone size during the first cycle is quite accurate. The numerical and analytical zone sizes deviate with increase in the number of thermal cycles, because the analytical derivation does not account for the residual stresses that arise as the system cycles and ratchets.

The strains, $\epsilon_{\mathrm{pl}}$, that accumulate within the plastic zone increase systematically with the number of cycles. This is exemplified by the distributions present after 12 cycles (Fig. 5A) and by monitoring the evolution of the plastic strain at the location of its maximum value (Fig. 6). The evolution of the plastic strains has the characteristics depicted in Fig. 6B. In the first cycle, initial yielding on cooling and reverse yielding on heating are apparent, as well as the changes in the incidence of forward and reverse yielding with the subsequent cycles. The adjustments are consistent with those noted above for the plastic zone size (Fig. 4A). The change in the accumulated strain with the number of cycles is shown in Fig. 7. After 12 cycles, the plastic strain reaches almost $10 \%$. This is the strain that accommodates the displacement of the TGO into the bond coat, manifest as an increase in the undulation amplitude with the number of cycles (Fig. 8A). The specific undulation growth rate, $\mathrm{d} A / \mathrm{d} N$, is governed by the growth strain, $\epsilon_{\mathrm{g}}$ (Fig. $8 \mathrm{~B}$ ). The criticality of the growth strain is visualized by arresting this strain after a few cycles (Fig. 8C). Note that, absent $\epsilon_{\mathrm{g}}$, the ratcheting stops even though the bond coat and the TGO are allowed to yield.

For a bond coat having higher yield strength, $\sigma_{\mathrm{Y}}^{\mathrm{bc}}=400 \mathrm{MPa}$, the corresponding results (Figs 3-8) reveal that the plastic-zone size, the plastic strains and the imperfection amplitude all increase during the first few cycles. But, thereafter, their enlargement stops, indicative of shakedown. The yield zones are depicted on Fig. 3(C and D). A key differentiator from the lower $\sigma_{\mathrm{Y}}^{\text {bc }}$ is the absence of reverse yielding. The plastic zone size, $R_{\mathrm{pl}}$ is plotted in Fig. $4 \mathrm{~B}$ and the imperfection amplitude, A, on Fig. 8(A and B). The plastic strain distribution is revealed on Fig. 5B. The accumulation of the plastic strain is indicated in Fig. 6B and its variation with $N$ plotted in Fig. 7 .

The results of calculations conducted for a wider range of $\sigma_{\mathrm{Y}}^{\mathrm{bc}}$ up to 24 cycles, expressed in terms of the change in imperfection amplitude (Fig. 8A) and the cumulated plastic strain (Fig. 7), suggest the fol- 


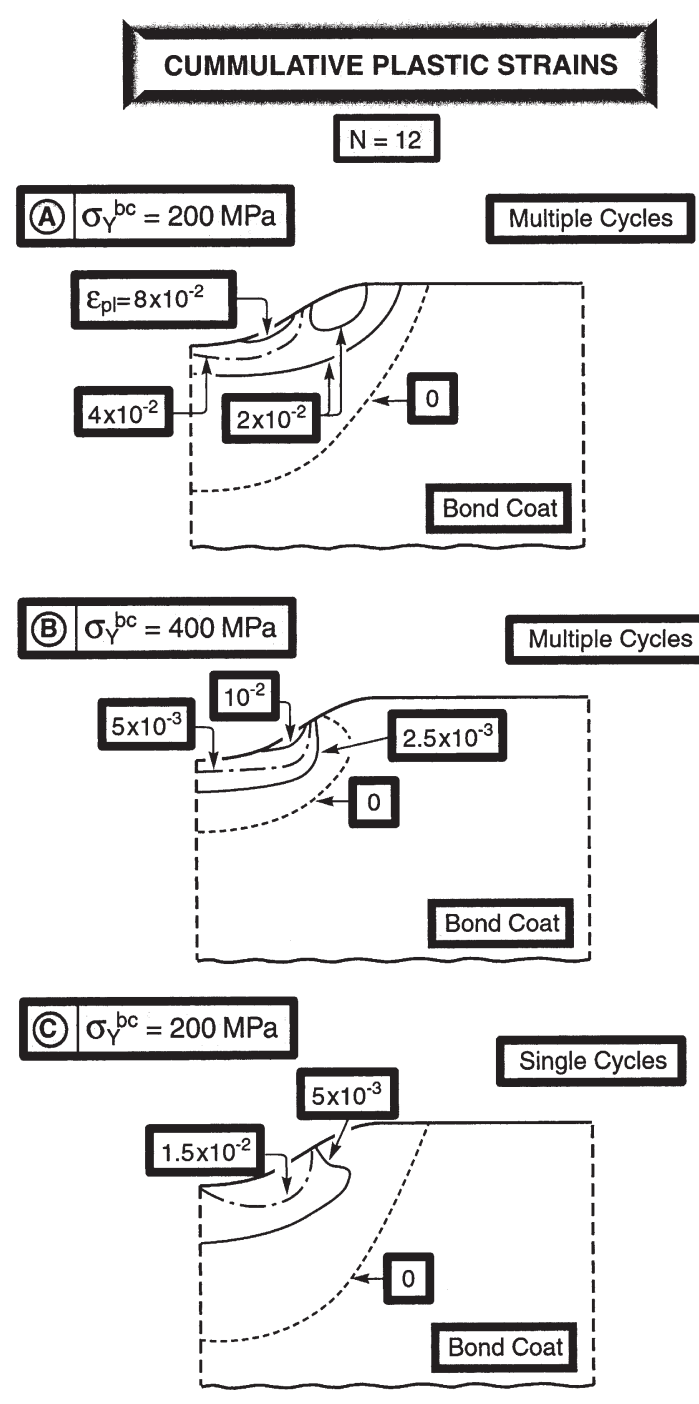

Fig. 5. Cumulative plastic strains in the bond coat when: (A) $\sigma_{\mathrm{Y}}^{\mathrm{bc}}=200 \mathrm{MPa}$; (B) $\sigma_{\mathrm{Y}}^{\mathrm{bc}}=400 \mathrm{MPa}$, both for multiple cycles; and (C) $\sigma_{\mathrm{Y}}^{\mathrm{bc}}=200 \mathrm{MPa}$ for single cycle. For all cases, $N=12$, whereupon the total growth strain applied is $11 \epsilon_{\mathrm{g}}\left(\epsilon_{\mathrm{g}}=10^{-3}\right)$.

lowing situation. When $\sigma_{\mathrm{Y}}^{\text {bc }}<250 \mathrm{MPa}$, reverse yielding occurs in the first cycle, whereupon $R_{\mathrm{pl}}, \epsilon_{\mathrm{pl}}$ and $A$ all continue to increase on a cycle-to-cycle basis, with no discernable limit. Conversely, when $\sigma_{\mathrm{Y}}^{\mathrm{bc}}$ is larger, there is no reverse yielding, whereupon the changes in plastic zone size, plastic strain and imperfection amplitude decrease significantly or stop after a few cycles. This yield strength thus appears to represent a bifurcation between ratcheting and shakedown. This conclusion will be elaborated in the discussion.

3.1.2. Cyclic stresses in the TGO. Further understanding is gained by monitoring the stress changes occurring in the TGO at the two levels of $\sigma_{\mathrm{Y}}^{\mathrm{bc}}$. The stresses tangential to the TGO/BC interface are investigated in Fig. 9. At the higher $\sigma_{\mathrm{Y}}^{\mathrm{bc}}$ (Fig. 9C and D), the stresses become spatially uniform after about eight cycles and invariant in magnitude with further

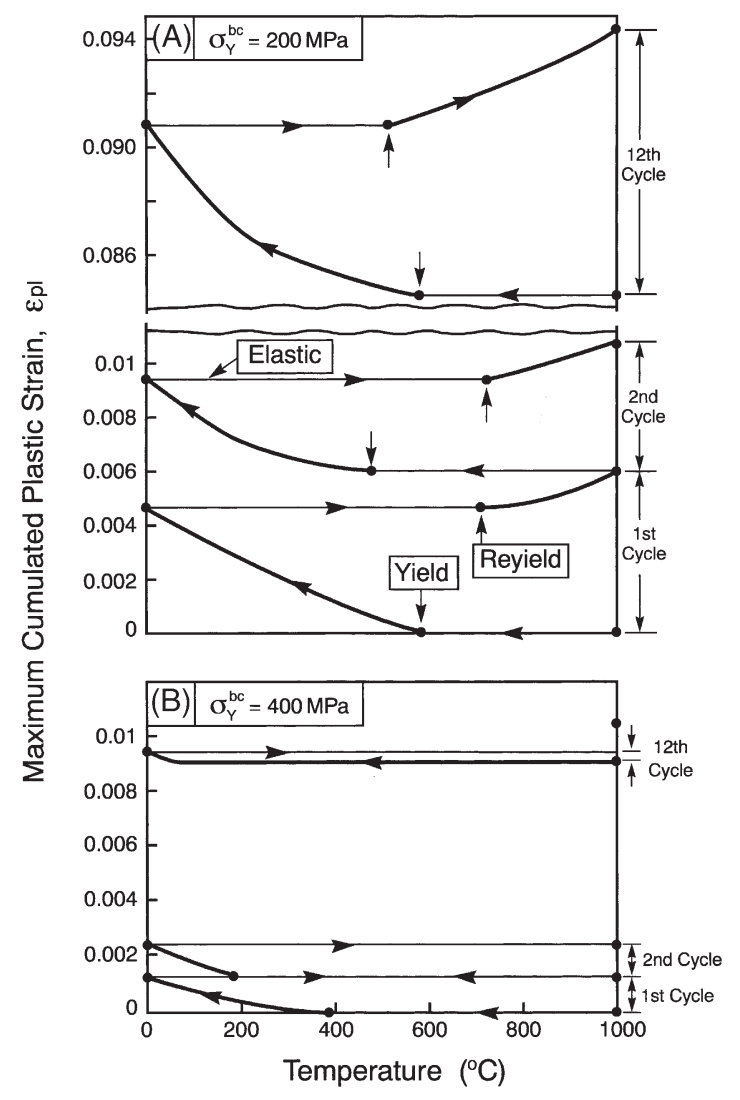

Fig. 6. Evolution of the maximum value of the cumulated plastic strain in the bond coat upon thermal cycling: (A) $\sigma_{\mathrm{Y}}^{\text {bc }}=200 \mathrm{MPa}$; (B) $\sigma_{\mathrm{Y}}^{\text {bc }}=400 \mathrm{MPa}$ (first, second and twelfth cycles).

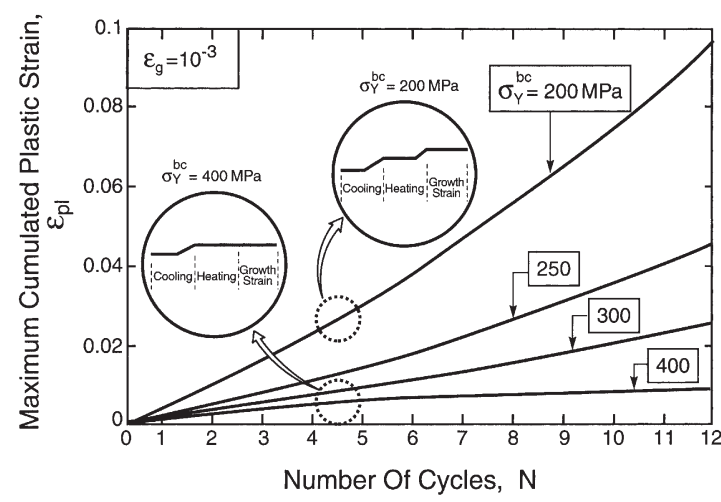

Fig. 7. Evolution of the maximum value of the cumulated plastic strain in the bond coat over 12 cycles.

cycling, indicative of a cyclic "steady-state". They are at yield at the peak temperature (about $-1 \mathrm{GPa}$ ) and reach $-4 \mathrm{GPa}$ at ambient. Accordingly, after the first few cycles, all subsequent growth strains are "absorbed" by TGO yielding at the peak temperature, accounting for the lack of further changes in plastic zone size and in undulation amplitude. Conversely, at the lower $\sigma_{\mathrm{Y}}^{\mathrm{bc}}$, spatial variations in the TGO stress persist (Fig. 9A and B). At elevated temperature, the 
stresses are mostly below yield. They are tensile in some sections of the imperfection (up to $1 \mathrm{GPa}$ ), yet in compression elsewhere, indicative of bending. At ambient, the TGO is in compression everywhere, but the stress is lower at the undulation than along the planar segments. This spatial variability is retained as cycling proceeds. Since the TGO is unable to take up the stress-free strain from growth, the bond coat must
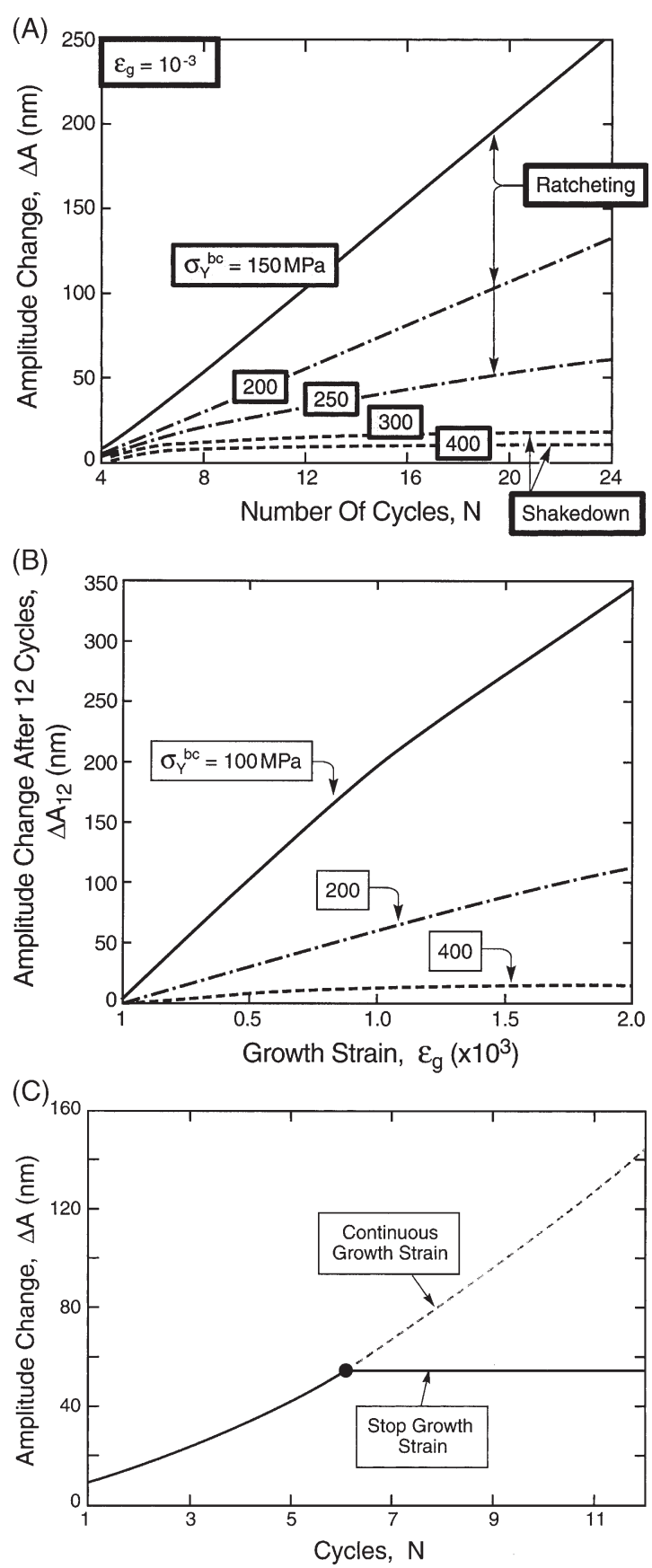

Fig. 8. (A) Undulation amplitude change over 24 cycles for a range of $\sigma_{\mathrm{Y}}^{\text {bc }}$. (B) Undulation amplitude change as a function of growth strain, $\epsilon_{\mathrm{g}}$. (C) Simulation showing that growth of the undulation amplitude discontinues when the growth strain is stopped.

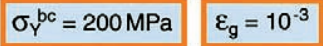

(A) AMBIENT TEMPERATURE

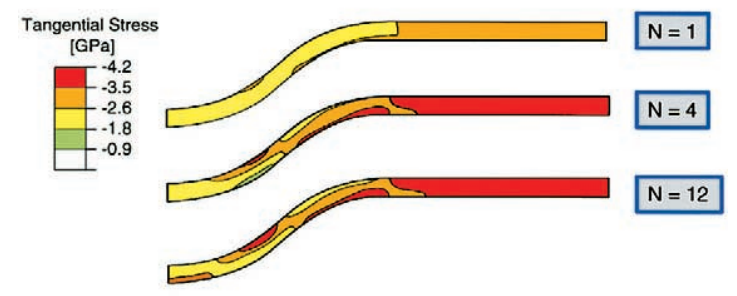

\section{(B) HIGH TEMPERATURE}

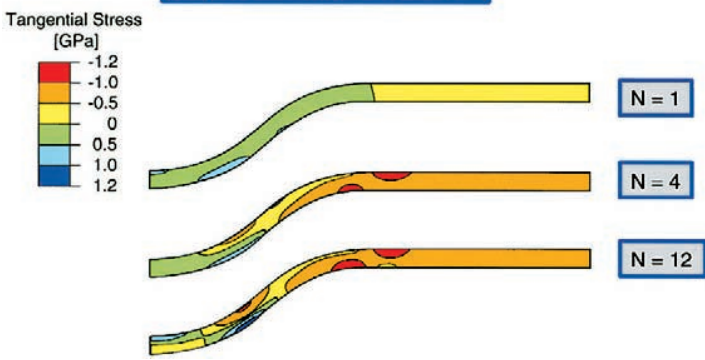

$\sigma_{\mathrm{Y}}^{\mathrm{bc}}=400 \mathrm{MPa} \quad \varepsilon_{g}=10^{-3}$

(C) AMBiENT TEMPERATURE

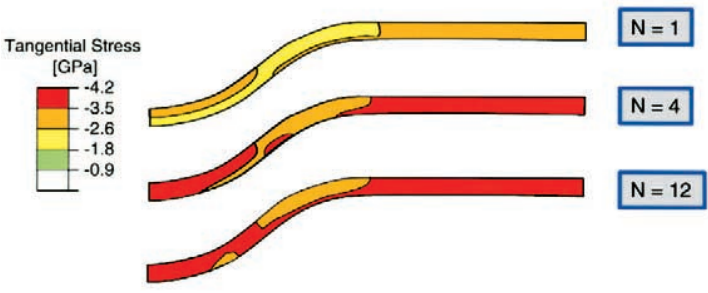

(D) HIGHTEMPERATURE

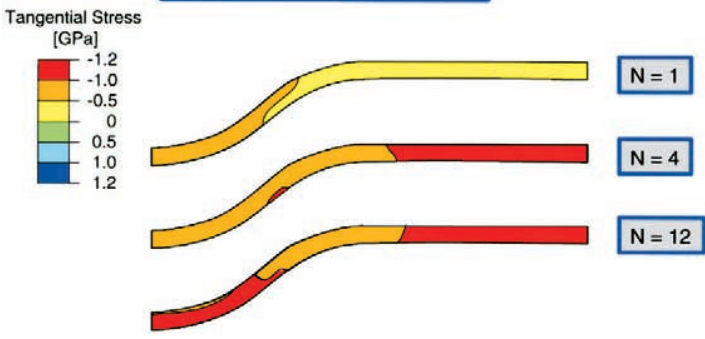

Fig. 9. Evolution of the tangential stress distribution in the TGO upon thermal cycling (first, fourth and twelfth cycle). For $\sigma_{\mathrm{Y}}^{\text {bc }}=200 \mathrm{MPa}$ : (A) ambient temperature; and (B) peak temperature. For $\sigma_{\mathrm{Y}}^{\text {bc }}=400 \mathrm{MPa}$ (C) ambient temperature; and (D) peak temperature. (Stresses tangential to the TGO/BC interface.) 
continue to "absorb" it, resulting in systematic changes in plastic strain and imperfection amplitude.

3.1.3. Isothermal response. As a further probe of the effects of temperature cycling, some of the results above are compared with the "single-cycle" response. That is, after the first half cycle, the material is held at temperature long enough to accumulate a growth strain, $(N-1) \epsilon_{\mathrm{g}}$, then cooled to ambient and reheated. The imperfection amplitude that ensues is compared with that obtained after $N$ cycles, each subject to strain, $\epsilon_{\mathrm{g}}$ (except in the final cycle). The results (Fig. 10) indicate that, in all cases, the cyclic amplitude change is larger than the isothermal, with the difference increasing as $\sigma_{\mathrm{Y}}^{\text {bc }}$ decreases. Similarly, the plastic strains are appreciably smaller after isothermal exposure than upon cycling (see Fig. 5C). The implication is that, upon cycling, whenever the condition for reverse yielding is established, a "reset" process appears to be installed and plastic straining continues with each thermal cycle, with no discernable limit. This effect is absent under isothermal conditions.

\subsection{Role of thermal expansion misfit between bond coat and substrate}

The role of the thermal expansion misfit between the bond coat and the substrate is explored on Figs 11 and 12. Two cases have been considered. One in which the bond coat has a larger thermal expansion coefficient than the substrate (positive misfit) and the other lower (negative misfit). In both cases, the misfit is $\left|\alpha_{\mathrm{bc}}\right| \mathrm{ppm} /{ }^{\circ} \mathrm{C}$ : the substrate has thermal expansion $14.3 \mathrm{ppm} /{ }^{\circ} \mathrm{C}$. The calculations reveal that, for both cases, the amplitude change is higher than for a bond coat with $\Delta \alpha_{\mathrm{bc}}=0$ (Fig. 11). Moreover, relative to expansion matched systems, ratcheting persists (no shakedown) for appreciably larger $\sigma_{\mathrm{Y}}^{\mathrm{bc}}$.

Thermal expansion misfit between the bond coat and the substrate, $\Delta \alpha_{\mathrm{bc}}$, can be regarded as a source of an "applied" stress, $\sigma_{\infty}$

$$
\sigma_{\infty}=\frac{E_{\mathrm{bc}} \Delta \alpha_{\mathrm{bc}} \Delta T}{1-v_{\mathrm{bc}}} .
$$

A fully-plastic state occurs when $\sigma_{\infty} \rightarrow \sigma_{\mathrm{Y}}^{\mathrm{bc}}$. For example, when $\Delta \alpha_{\mathrm{bc}}= \pm 3 \mathrm{ppm} /{ }^{\circ} \mathrm{C}$, this happens on cooling whenever $\sigma_{\mathrm{Y}}^{\mathrm{bc}} \leq 800 \mathrm{MPa}$. Fully-plastic reverse yielding on re-heating requires that $\sigma_{\mathrm{Y}}^{\text {bc }}$ be lower by a factor of 2 . Thus, when $\Delta \alpha_{\mathrm{bc}}= \pm 3 \mathrm{ppm} /{ }^{\circ} \mathrm{C}$, reverse yielding happens whenever $\sigma_{\mathrm{Y}}^{\mathrm{bc}} \leq 400 \mathrm{MPa}$. This assessment is consistent with the finite element results, which also demonstrate how general straining interacts with the localized strains around the undulation to cause the cyclic plasticity (Fig. 12), considered to be the source of the enhanced ratcheting. Now, the plastic zones have more complex (nonspherical) shape, because of the interaction. Specifically, when the misfit causes the bond coat to be in residual tension upon cooling, plastic straining is enhanced at the base of the imperfection, because the misfit-induced, in-plane, tension [10] enhances the stress caused by the TGO (Fig. 12C and D). On reheating, reverse yielding is more prevalent around the sides of the imperfection, resulting in a toroidal plastic zone (Fig. 12C and D). For the converse misfit, the in-plane compression induced on cooling [10]
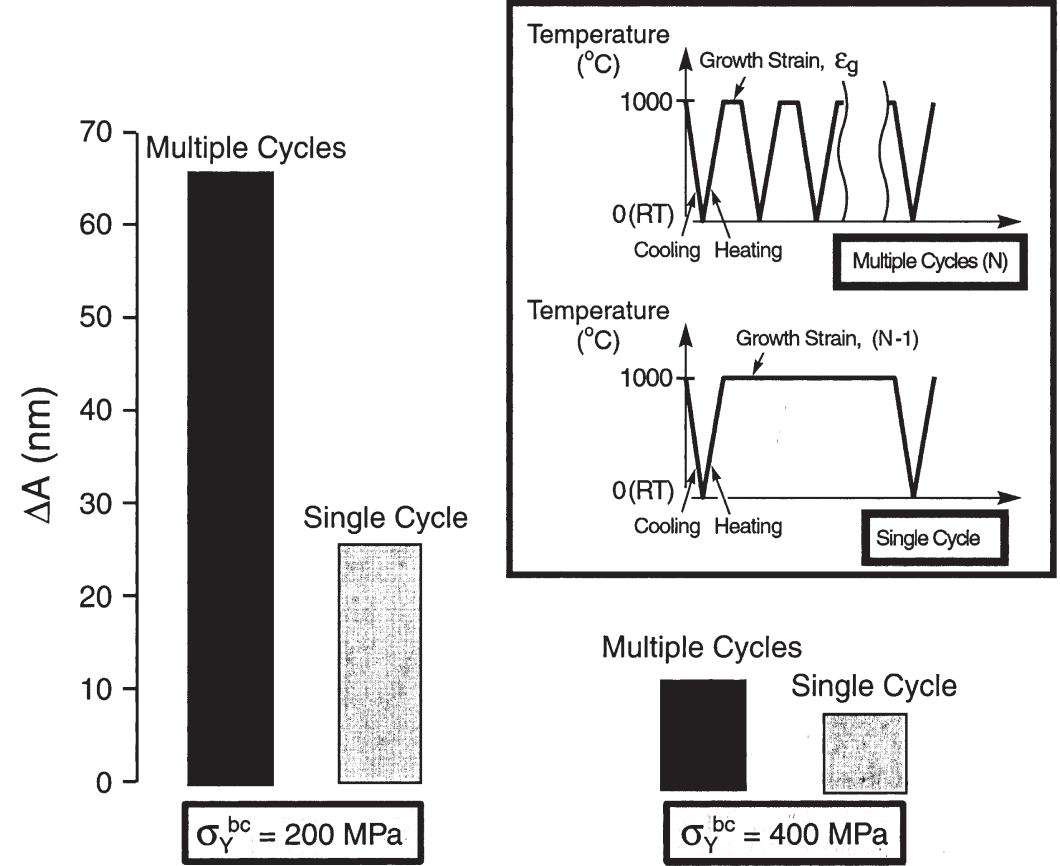

Fig. 10. Undulation amplitude change for multiple cycles compared to that for a single cycle. For both cases $N=12$, whereupon the total growth strain is $11 \epsilon_{\mathrm{g}}\left(\epsilon_{\mathrm{g}}=10^{-3}\right)$. 


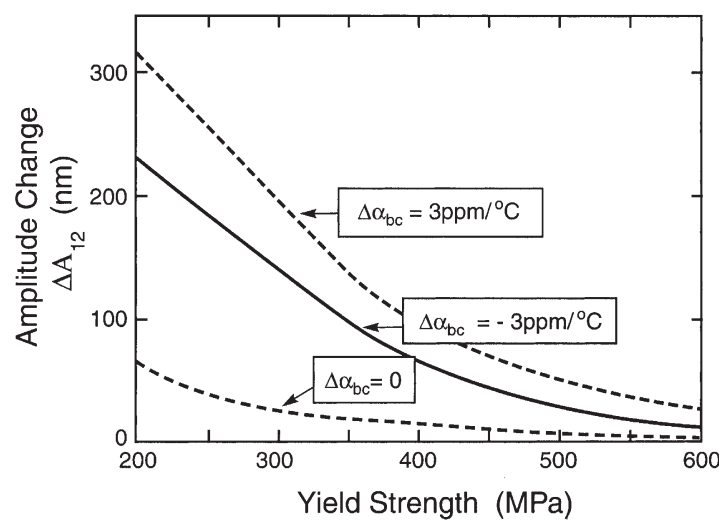

Fig. 11. Undulation amplitude change over 12 cycles in the presence of a thermal misfit (positive or negative) between bond coat and substrate.

suppresses plastic straining beneath the imperfection, but enhances it at the sides (Fig. 12A and B). Moreover, a larger reverse plastic zone develops on reheating (Fig. 12A and B). Regardless of the details, the misfit always appears to facilitate cyclic yielding around imperfections and broadens the incidence of ratcheting to encompass stronger bond coats.

A more detailed analysis is needed to provide the fundamental understanding needed to predict the influence of the expansion misfit on the ratcheting domain, especially within the context of a ratcheting map.

3.2.1. Temperature dependent yielding. All practical bond coats have a yield strength that varies strongly with temperature $[15,17]$. A prototypical variation for $\beta$ - $(\mathrm{NiAl})$ alloys has been shown on Fig.
2. To demonstrate the consequences for yielding and ratcheting, the high and low temperature levels of yield strengths, $\sigma_{\mathrm{Y} \text { min }}^{\text {bc }}$ and $\sigma_{\mathrm{Y} \max }^{\mathrm{bc}}$, respectively, are defined (Fig. 2) and varied over a range that encompasses the measured values. Some simulations conducted with in the range $200 \mathrm{MPa}$ to $1 \mathrm{GPa}$ and $\sigma_{\mathrm{Y} \text { min }}^{\text {bc }}=50 \mathrm{MPa}$ are shown on Figs 13 and 14. The larger $\sigma_{\mathrm{Y} \text { max }}^{\mathrm{bc}}$ is representative of actual bond coats. The lower value is used to explore some trends and also to address responses in bond coats, such as $\gamma^{\prime}$ alloys, that can have quite low yield strength at ambient $[15,17]$.

The differences relative to temperature-invariant yielding are as follows. The bond coat is now sufficiently soft at high temperature that some plastic deformation occurs during the TGO growth phase, adding to the accumulation of the plastic strain (Fig. 13A). Upon cooling, while the bond coat is still soft, the plastic zone size and the plastic strains both increase, but plastic straining ceases at a temperature, $T_{\text {tr }}$ (about $900^{\circ} \mathrm{C}$ ). Thereafter, the expansion misfit is accommodated strictly by elastic straining and, consequently, upon re-heating back to $T_{\text {tr }}$, the system simply "unloads". Reverse yielding occurs when the temperature approaches the peak. Even though the reverse yield zone is small, it appears to be sufficient to "reset" the stresses, thus promoting ratcheting and increasing the amplitude of the imperfection. The change in the accumulated plastic strain with number of cycles is plotted in Fig. 13B. The corresponding change in the undulation amplitude is plotted on Fig. 14 , where it is compared with the result for constant yield strength, $\sigma_{\mathrm{Y}}^{\mathrm{bc}}=200 \mathrm{MPa}$. Note that the ratcheting rate is somewhat higher with the temperature

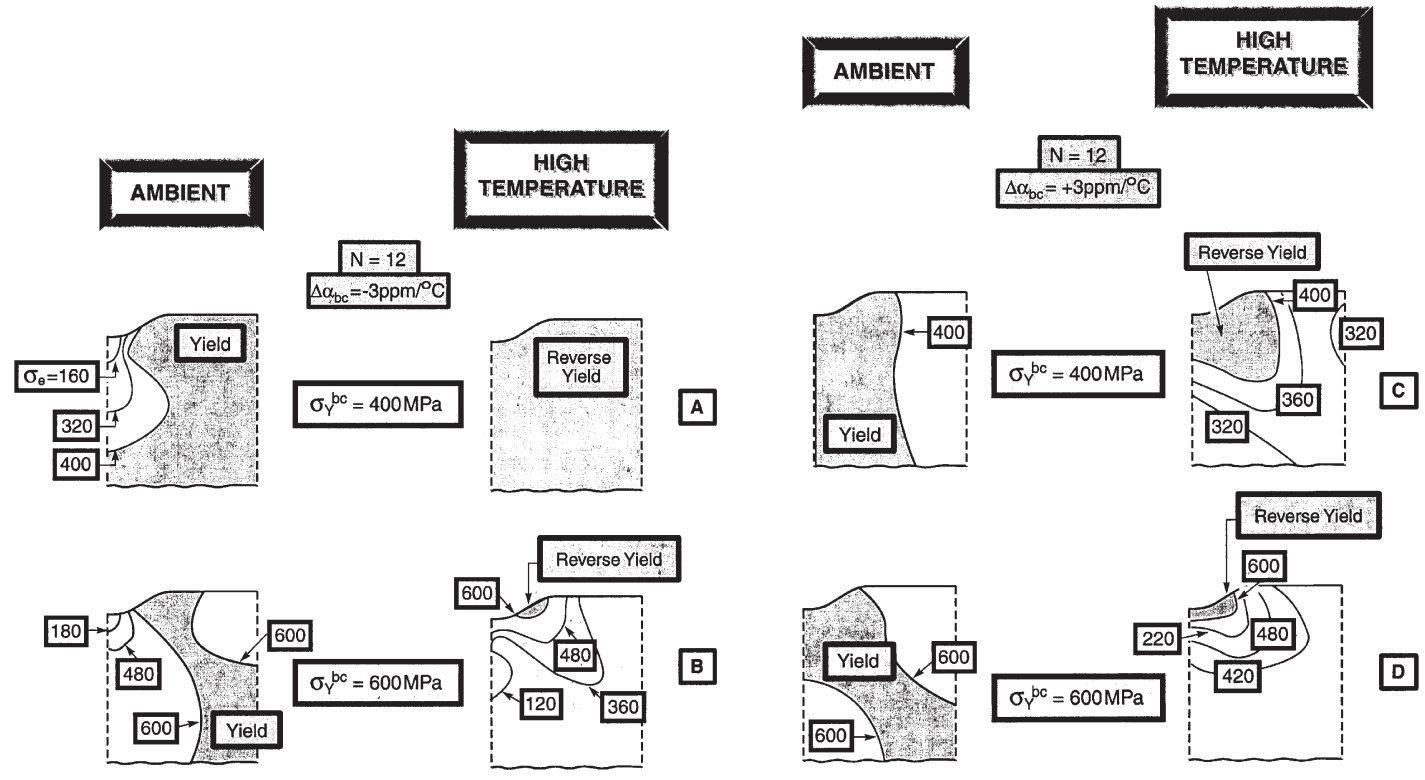

Fig. 12. Plastic zone and effective stress distribution in the bond coat in the presence of thermal mismatch between the bond coat and substrate after 12 cycles. For the case of $\alpha_{\mathrm{bc}}=-3 \mathrm{ppm} /{ }^{\circ} \mathrm{C}$ : (A) $\sigma_{\mathrm{Y}}^{\mathrm{bc}}=400 \mathrm{MPa}$ and (B) $\sigma_{\mathrm{Y}}^{\mathrm{bc}}=600 \mathrm{MPa}$. For the case of $\alpha_{\mathrm{bc}}=+3 \mathrm{ppm} /{ }^{\circ} \mathrm{C}$ : (C) $\sigma_{\mathrm{Y}}^{\mathrm{bc}}=400 \mathrm{MPa}$ and (D) $\sigma_{\mathrm{Y}}^{\mathrm{bc}}=600 \mathrm{MPa}$. 


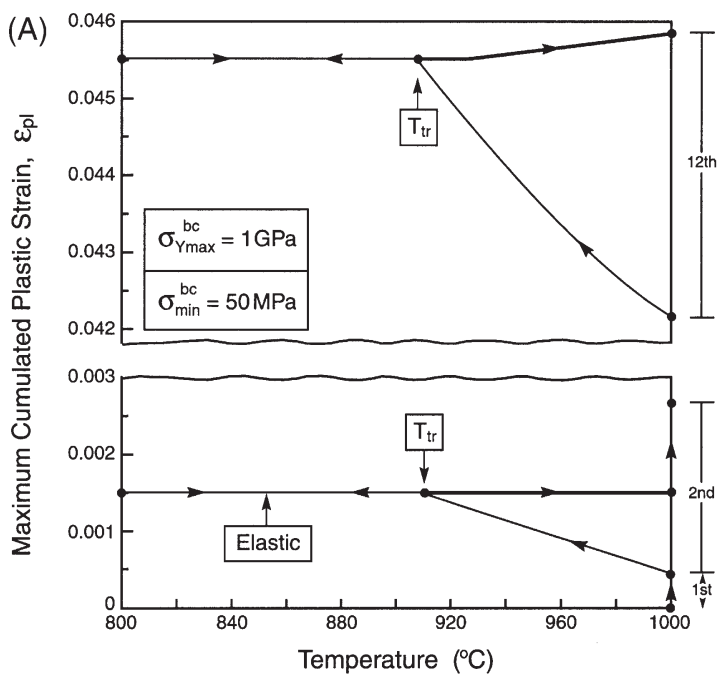

(B)

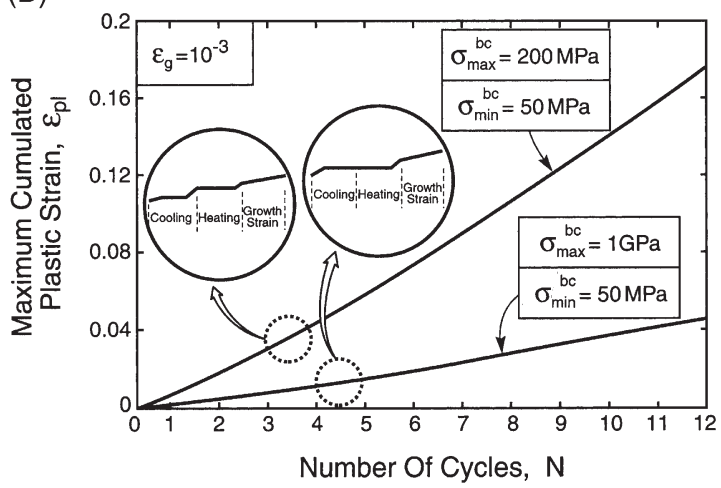

Fig. 13. Evolution of the maximum value of the cumulated plastic strain in the bond coat for a bond coat with a temperature dependent yield strength (A) upon thermal cycling (first, second and twelfth cycle), and (B) over 12 cycles.

dependent yield strength, despite the large yield strength at ambient. Again, ratcheting correlates with the incidence of reverse yielding.

These results are preliminary and a detailed understanding still needs to be developed. Nevertheless, one implication is that ratcheting displacements are fully developed when the temperature reaches $T_{\mathrm{tr}}$ : further cooling has no effect. This prediction is amenable to experimental assessment.

\section{IMPLICATIONS AND CONCLUSIONS}

Displacement instabilities in the thermally grown oxide originating from initial interface imperfections have been simulated by developing and using a numerical code. The emphasis has been on factors that exert the key influence on the instability. The simulation has been based on a range of phenomena and constituent properties. It involves plasticity in the bond coat, growth strains in the TGO, thermal expansion misfit between the TGO, bond coat and substrate, as well as stress relaxation in the TGO at high temperature. In order to explore the fundamentals of the

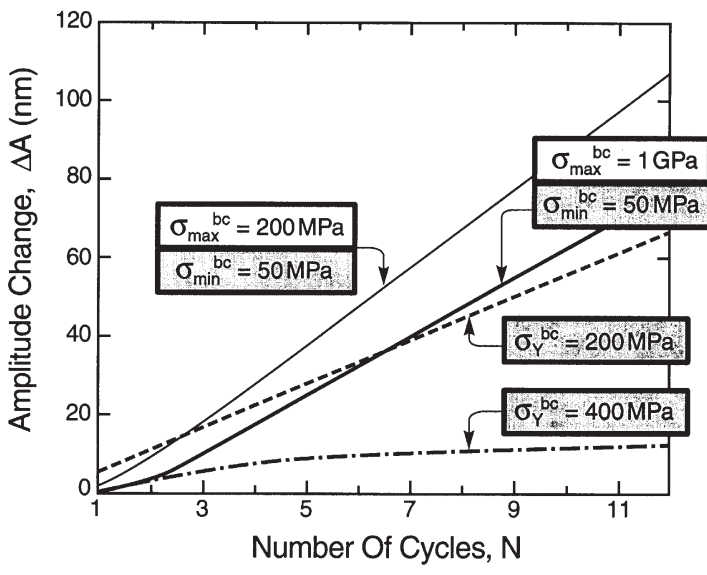

Fig. 14. Undulation amplitude change over 12 cycles for temperature dependent yield strength of bond coat, for two different $\sigma_{\mathrm{Y} \max }^{\text {bc }}$.

cyclic plasticity occurring in the bond coat, around the imperfections, plastic zone development upon temperature cycling has been simulated, as well as the associated plastic strains. Changes in the amplitude of the imperfections have been determined as the system cycles. The stresses in the TGO have also been monitored. One of the key implications is that the incidence of reverse yielding upon reheating differentiates between ratcheting and shakedown. That is, whenever the conditions for reverse yielding is satisfied during the initial cycle, the system ratchets. Otherwise, shakedown occurs. The situation is visualized on Fig. 15. For a bond coat having a temperature invariant yield strength, this transition occurs at a yield strength of about $250 \mathrm{MPa}$ for the configuration analyzed in the study. For the small overall thickening investigated in this article, there is no significant change in transitional yield strength as the TGO grows. However, some effects are expected when larger changes in thickness are explored in the ongoing study.

That the instability can only occur for such "soft" bond coats $\left(\sigma_{\mathrm{y}}^{\mathrm{bc}} \leq 250 \mathrm{MPa}\right)$ is inconsistent with the experimental findings $[4,13]$. Two other effects that expand the ratcheting domain have thus been explored.

1. One is the thermal expansion misfit between the bond coat and the substrate. It has been found from simulations that such misfit enhances ratcheting by expanding the zone that experiences cyclic yielding.

2. The second relates to the temperature dependence of the yield strength: the bond coat being relatively soft at high temperature, but strong at ambient.

In such cases, most of the cyclic plasticity occurs over a narrow temperature range close to the peak temperature. One consequence is an appreciably enhanced ratcheting domain, even when the bond coat 


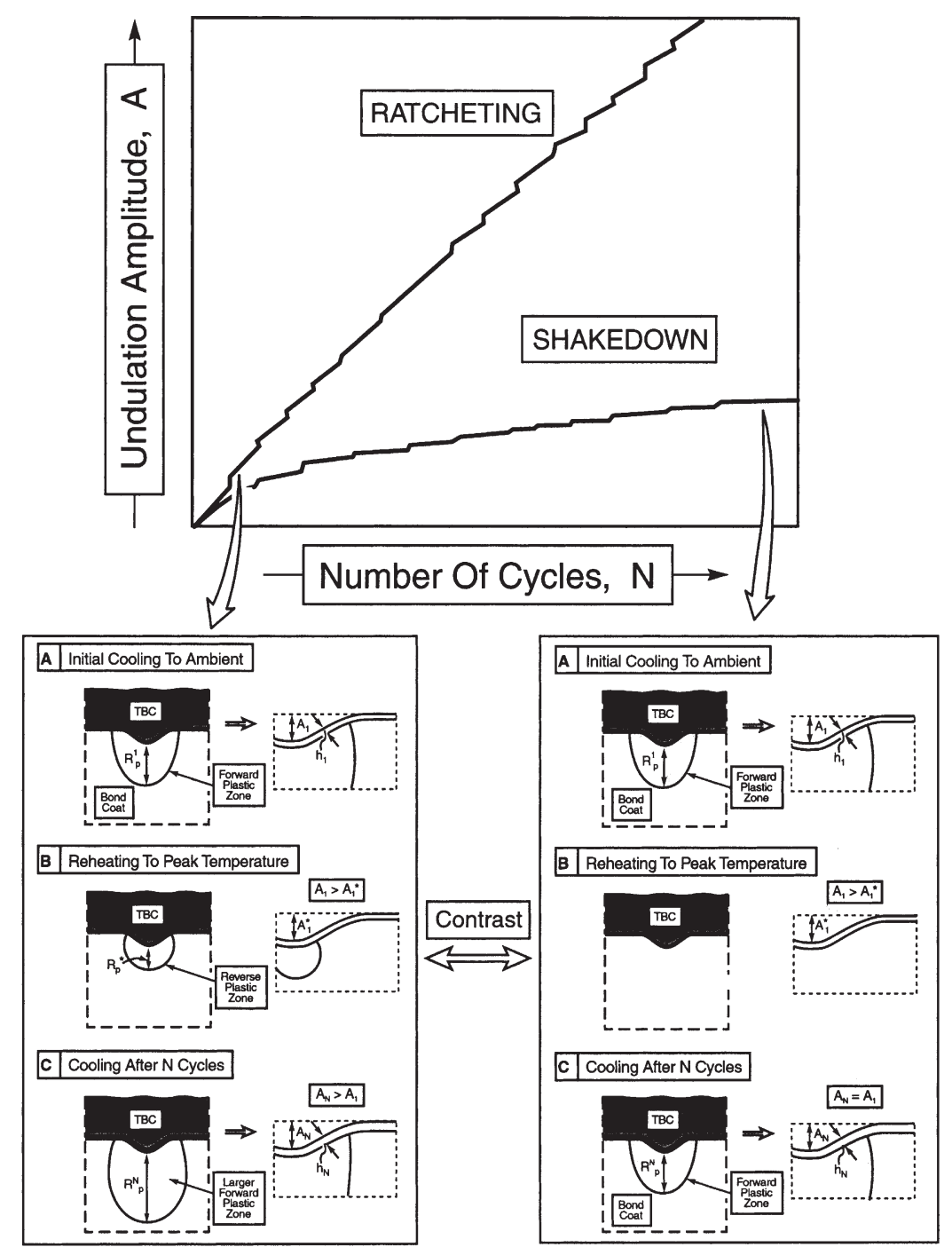

Fig. 15. Schematic showing how the initiation of the reverse yielding governs the subsequent changes in undulation amplitude with thermal cycling.

has ambient temperature strength in the $1 \mathrm{GPa}$ range. Another consequence is that the ratcheting-rate is fully realized when the minimum temperature in the thermal cycle is in the $900^{\circ} \mathrm{C}$ range. Cooling to ambient is not required.

While the simulations have "unearthed" several phenomena that appear to be centrally related to the occurrence of ratcheting, such as thermal expansion misfit between the bond coat and the substrate, as well as the temperature dependence of yielding, the fundamentals remain to be addressed. This would require a comprehensive series of calculations and correlation with the experimental findings. Such details will be addressed in a subsequent study.

Acknowledgements-This work was supported in part by the Office of Naval Research under ONR Contract No. N0001499-10170

\section{REFERENCES}

1. Miller, R. A., J. Am. Ceram. Soc., 1984, 67, 517.

2. Strangman, T. E., Thin Solid Films, 1985, 127, 93.

3. Wright, P. K. and Evans, A. G., Current Opinion in Solid State \& Materials Science, 1999, 4, 255.

4. Stiger, M. J., Yanar, N. M., Topping, M. G., Pettit, F. S. and Meier, G. H., Z. Metallkd., 1999, 90(12), 1069.

5. DeMasi-Marcin, J. T. and Gupta, D. K., Surface and Coatings Technology, 1994, 68/69, 1.

6. Evans, A. G., Mumm, D. R., Hutchinson, J. W., Meier, G. H. and Pettit, F. S., Prog. Mater. Sci. (in press).

7. Tolpygo, V. K., Dryden, J. R. and Clarke, D. R., Acta mater., 1998, 46, 927.

8. Tolpygo, V. K. and Clarke, D. R., Acta mater., 2000, 48, 3283.

9. He, M. Y., Evans, A. G. and Hutchinson, J. W., Acta mater., 2000, 48, 2593.

10. Ambrico, J. M., Begley, M. R. and Jordan, E. H., (submitted for publication).

11. Gell, M., Vaidyanathanm, K., Barber, B., Cheng, J. and Jordan, E., Metall. Mater. Trans. A, 1999, 30A, 427. 
12. Mumm, D. R. and Evans, A. G., Acta mater., 2000, 48, 1815.

13. Mumm, D. R., Spitsberg, I. and Evans, A. G., Acta mater. (in press).

14. Rhines, F. N. and Wolf, J. S., Metall. Trans., 1970, 1, 1701.
15. Darolia, R., private communication.

16. Watanabe, M., Mumm, D. R. and Evans, A. G., (in preparation).

17. Strangman, T. E., Ph.D. Thesis, University of Connecticut, 1978. 